\title{
PRECISIONES SOBRE LA SINAGOGA DE MIRANDA DE EBRO
}

INOCENCIO CADIÑANOS BARDECI

Como toda judería importante, la de Miranda de Ebro (Burgos) también tuvo su sinagoga. Muy transformada al poco tiempo de la expulsión hebrea, hoy no quedan restos; por ello su localización ha presentado muchas dudas.

Cierto documento de mediados del siglo XV menciona la existencia de dicha sinagoga. Otro de 1493 nos asegura que se hallaba en la calle de la Puente, precisando que se encontraba "cerca de la Puerta de la Villa», o sea, a sus comienzos. La calle de la Puente es la misma que hoy es conocida popularmente como calle de los Judíos y oficialmente denominada de la Independencia. Paralela al Ebro, se corresponde con el tramo limitado por dos de los cuatro ingresos de las murallas entonces existentes. Se trata de las desaparecidas puertas de la Villa (o de la Puente) y del Valle, en la parte baja. Cuando en el siglo XVII era ampliado el palacio de los Urbina, todavía quedaba el recuerdo judío: "que ambos [palacios, de los Urbina y Berberana se hallan], a la plaza que llaman del Rey, y salen ambos al corral que llaman de los Judíos y vistas del río Hebro" '. Contemporáneamente aparece una cercana callejuela denominada del Rabino (después enmascarada bajo el nombre del Racimo), que hoy se corresponde con la travesía de la Fuente.

El primero que intentó fijar el emplazamiento de la sinagoga fue el profesor Francisco Cantera -en un principio parece que atinadamente- situándola en dicha calle. Pero en 1961, al descubrirse cierta vivienda de notable construcción en la calle de la Fuente, cambió de opinión emplazándola en dicha casa, señalada hoy con

' I. CADIÑANos BARDECI, «Documentos para la historia del arte en Miranda de Ebro y sus contornos", Estudios Mirandeses XI (1992) 29-68. 
un rótulo que así la denomina. Para ello tuvo que forzar un tanto la documentación. Por ejemplo, transcribió la palabra "puente por "fuente" ${ }^{2}$. Pero su lejanía del barrio judío, la propia documentación y otros diversos motivos, mantuvieron la duda. Recientemente José Luis Lacave, con mayor acierto, ha emplazado la sinagoga en la travesía de la Fuente ${ }^{3}$. Josefina Andrío, sin embargo, sigue admitiendo la reducción del profesor Cantera, aunque también con ciertas reservas ${ }^{4}$. Creo que hoy hay que ubicarla en un punto bastante distinto, puesto que el análisis de la documentación deja muy pocas o ninguna duda.

Tras la expulsión, el edificio de la sinagoga - que, como tantos otros, no debía de presentar un especial mérito artístico- fue donado al concejo mirandés. Efectivamente, este concejo solicitó de los Reyes Católicos que ni la sinagoga ni el fonsario fueran enajenados, con el fin de destinar la primera para iglesia. Después cambió de opinión y la demandó para casa de reuniones por no disponer de ella su Ayuntamiento y resultar «logar convenible». Así lo concedieron los Reyes por orden de 12 de junio de 1493. Dado que la pequeña Casa Consistorial se hallaba entonces en la última planta de la antes mencionada puerta de la Villa, a la entrada del puente, cerca debía de encontrarse necesariamente la casa de oración de los judíos.

El concejo pensó en acondicionarla para su nuevo destino, pero no se llevó a efecto. Como indica el documento que publicamos, la sinagoga de Miranda, junto con la sinagoga de Pancorbo, sería entregada por los Reyes a los monteros Fernando de Angulo y Pedro de Azcona en 1496. Posiblemente por sucesión o venta recayó en un particular que, años después, levantaría otra planta sobre ella.

El emplazamiento de la sinagoga en la citada calle de los Judíos, junto a la antigua puerta del Puente (o de la Villa) lo avalan otros documentos que, al mismo tiempo, también nos proporcionan otros detalles: «casa e synoga que auia seydo de los judios que es en la calle de la Puente, cerca de la puerta de la Villa». Según esto, podría precisarse que tuvo que encontrarse cerca de la llamada escalera del Valle. Se trata del lado lindante con las aguas del Ebro,

${ }^{2}$ F. CAntera Burgos, Sinagogas españolas, Madrid (1, pág. 246.

3 J. L. LaCaVE, Juderías y sinagogas españolas, Madriu 1992, pág. 191.

4 J. Andrío Gonzalo y F. Cantera Burgos, Historia medieval de Miranda de Ebro, Miranda de Ebro 1991, pág. 234. 


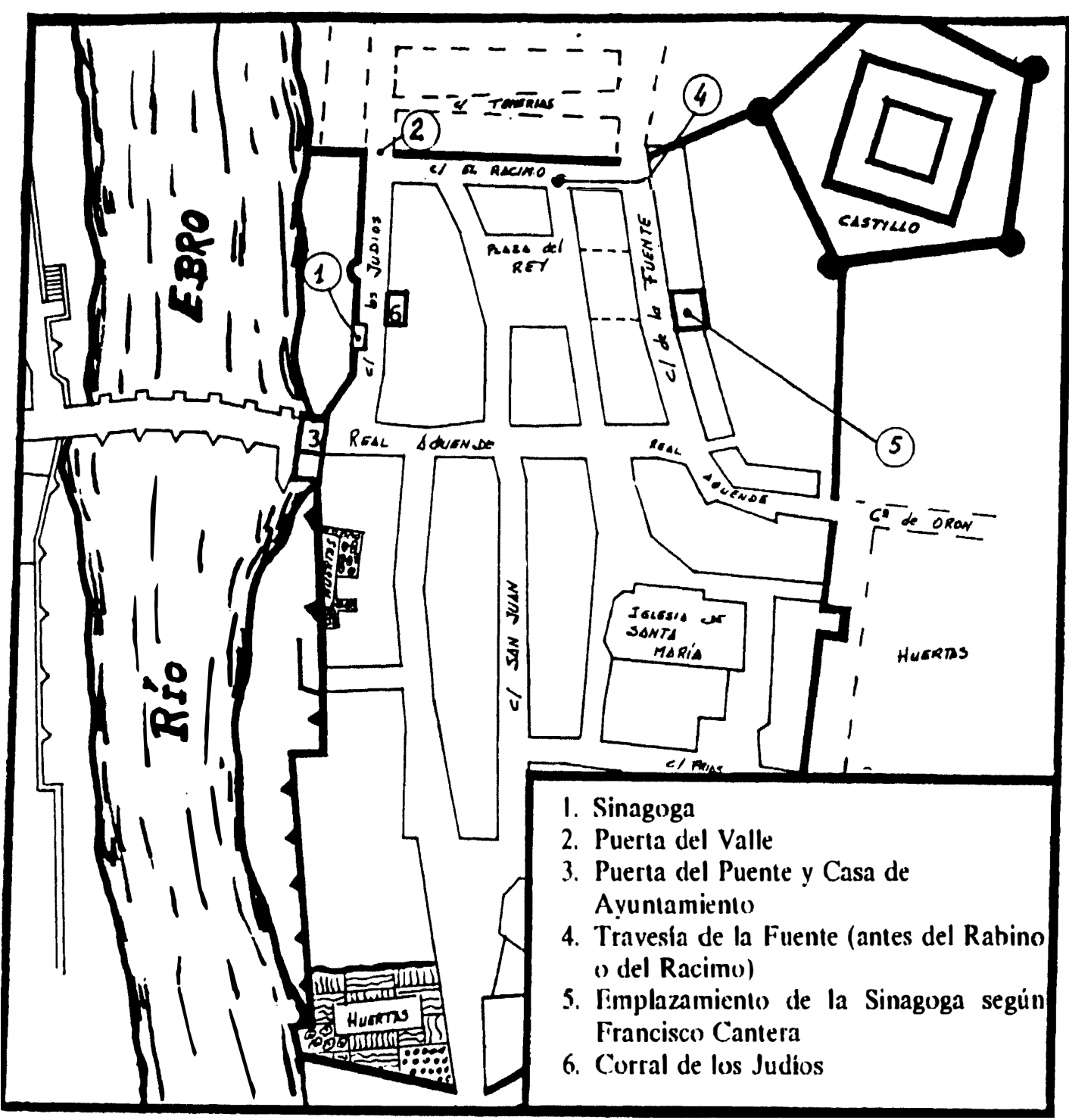

Miranda de Ebro. Sinagoga y calle de los Judíos (Sobre un dibujo de José Luis Montes)

hoy despejado, pero que en el pasado estaba defendido por la muralla o cerca. Tenía viviendas adosadas en su paramento interno, detalle que es seguro e importante para nuestra afirmación: ya hacia 1470 se hablaba de tales viviendas y, cuando en 1569 , el cantero Miguel Aguirre se comprometía a construir la antes mencionada escalera, la sitúa e identifica con «la baxada por donde antes el vivia». En 1530 se había acusado a un tal Ortega de Medinilla de «tener una casa edeficada sobre la cerca, en la parte donde solia ser synoga ... que asimismo hay otras muchas casas sobre las dichas 
cercas». El documento no deja lugar a dudas sobre el emplazamiento de la sinagoga.

En resumen, la sinagoga mirandesa se encontró a pocos metros del puente, adosada a la muralla lindante con el Ebro, en la todavía popular calle de los Judíos. Al ser demolida la cerca en el siglo pasado con el fin de ensanchar dicha calle, desapareció también el último recuerdo de la sinagoga, lo que ha dado lugar a las distintas opiniones que hemos expuesto.

\section{APÉNDICE DOCUMENTAL}

Donación de las sinagogas de Miranda de Ebro y Pancorbo

R.G.S: T. XIII, $\mathrm{n}^{\mathrm{Q}} 2.702$.

Don Fernando e doña Ysabel por la grazia de Dios etc. Por la presente fazemos saber a vos Ferdinando de Angulo, abad de Vivancos, Pero Hazcona, nuestros monteros de guarda por algunos buenos seruicios que nos avedes fecho e en alguna hemienda e renmuneraçion dellos, de las synogas que los judios dexaron en las villas de Miranda de Hebro e Pancoruo con todo lo que les pertenesçe segund e como los dichos judios las tenian e poseyan para que sean vuestras e de vuestros herederos e suçesores e podades fazer dellas e de cada vna dellas lo que quesieredes e por byen touieredes como de cosa vuestra propia, la qual dicha merced vos hazemos syn pernizion de a terçero e mandamos a los conçejos e alcaldes, alguaziles, regidores, cavalleros, escuderos e ofiçiales e omes buenos de las dichas villas de Miranda de Hebro e Pancoruo e a qualesquier reçebtores de los bienes de los dichos judios e a otras qualesquier personas a quien lo de yuso en esta mi carta contenido atañe o atañier puede en qualquier manera que luego que por vosotros o por la persona que vuestro poder para ello ouiere o fuere requeridos vos den e entreguen las dichas synogas con todo lo que les pertenesçe e vos pongan en la posesion dellas e ansy puesto vos amparen e defiendan en ella e vos dexen e consyentan libremente vsar dellas e daser dellas e en ellas como de cosa vuestra propia libre e quita e desenbargada syn contradiçion alguna e que en ello ni en cosa alguna nin parte dello enbargo nin ympedimento alguno vos non pongan nin consyentan poner. La qual dicha merced vos fazemos en la manera que dicha es syn perjuizio de terçero. E los vnos nin los otros non fagades nin fagan ende al por alguna manera so pena de la nuestra merced e de diez mill maravedis para la nuestra Camara... 
Dada en la çibdad de Burgos a veinte e tres dias del mes de dizienbre año del nasçimiento de nuestro señor Ihesuchristo de mill e quatroçientos e nouenta e seys años. Yo el Rey, yo la Reyna.

\section{RESUMEN}

El edificio de la sinagoga de Miranda de Ebro ha sido localizado en muy distintos puntos de la ciudad. Hoy, gracias a la aparición de nuevos documentos, podemos fijar con bastante precisión su emplazamiento. Se hallaba en la todavía denominada calle de los Judíos, adosada a las murallas que separaban y protegían dicha calle del cauce del Ebro.

\section{SUMMARY}

The building of the synagogue of Miranda de Ebro has been situated in many different places of the town. Nowadays, thanks to the publication of new documents, we can locate its site quite accurately. It was found in the Jews street which has kept the same name until now. It was leaning against the walls that separated and protected that street from the Ebro river-bed. 